\title{
Costs of treating patients with schizophrenia who have illness-related crisis events
}

\author{
Baojin Zhu1 ${ }^{1}$, Haya Ascher-Svanum*1, Douglas E Faries', Xiaomei Peng1, \\ David Salkever ${ }^{2}$ and Eric P Slade ${ }^{3,4}$
}

Address: ${ }^{1}$ Eli Lilly and Company, Indianapolis, USA, ${ }^{2}$ University of Maryland, Baltimore County (UMBC), Department of Public Policy, Baltimore, USA, ${ }^{3}$ University of Maryland School of Medicine, Baltimore, USA and ${ }^{4}$ U.S. Department of Veterans Affairs, VA VISN5 Mental Illness Research and Education Clinical Center, Baltimore, USA

Email: Baojin Zhu - ZHU_BAOJIN@LILLY.COM; Haya Ascher-Svanum* - haya@lilly.com;

Douglas E Faries - FARIES_DOUGLAS_E@LILLY.COM; Xiaomei Peng - PENG_XIAOMEI@lilly.com; David Salkever - SALKEVER@UMBC.EDU; Eric P Slade - ESLADE@PSYCH.UMARYLAND.EDU

* Corresponding author

Published: 26 August 2008

BMC Psychiatry 2008, 8:72 doi:10.1 186/147/-244X-8-72
Received: 12 December 2007

Accepted: 26 August 2008

This article is available from: http://www.biomedcentral.com/I47I-244X/8/72

(c) 2008 Zhu et al; licensee BioMed Central Ltd.

This is an Open Access article distributed under the terms of the Creative Commons Attribution License (http://creativecommons.org/licenses/by/2.0), which permits unrestricted use, distribution, and reproduction in any medium, provided the original work is properly cited.

\begin{abstract}
Background: Relatively little is known about the relationship between psychosocial crises and treatment costs for persons with schizophrenia. This naturalistic prospective study assessed the association of recent crises with mental health treatment costs among persons receiving treatment for schizophrenia.

Methods: Data were drawn from a large multi-site, non-interventional study of schizophrenia patients in the United States, conducted between 1997 and 2003. Participants were treated at mental health treatment systems, including the Department of Veterans Affairs (VA) hospitals, community mental health centers, community and state hospitals, and university health care service systems. Total costs over a Iyear period for mental health services and component costs (psychiatric hospitalizations, antipsychotic medications, other psychotropic medications, day treatment, emergency psychiatric services, psychosocial/rehabilitation group therapy, individual therapy, medication management, and case management) were calculated for I 557 patients with complete medical information. Direct mental health treatment costs for patients who had experienced I or more of 5 recent crisis events were compared to propensity-matched samples of persons who had not experienced a crisis event. The 5 non-mutually exclusive crisis event subgroups were: suicide attempt in the past 4 weeks $(n=18)$, psychiatric hospitalization in the past 6 months $(n=240)$, arrest in the past 6 months $(n=56)$, violent behaviors in the past 4 weeks $(n=62)$, and diagnosis of a co-occurring substance use disorder $(n=413)$.
\end{abstract}

Results: Across all 5 categories of crisis events, patients who had a recent crisis had higher average annual mental health treatment costs than patients in propensity-score matched comparison samples. Average annual mental health treatment costs were significantly higher for persons who attempted suicide $(\$ 46,024)$, followed by persons with psychiatric hospitalization in the past 6 months $(\$ 37,329)$, persons with prior arrests $(\$ 3 I, 08 I)$, and persons with violent behaviors $(\$ 18,778)$. Total cost was not significantly higher for those with co-occurring substance use disorder $(\$ 19,034)$.

Conclusion: Recent crises, particularly suicide attempts, psychiatric hospitalizations, and criminal arrests, are predictive of higher mental health treatment costs in schizophrenia patients. 


\section{Background}

Schizophrenia is among the most costly of all mental illnesses, with an estimated annual per person direct treatment cost that is approximately 2-fold higher than the cost of major depression and more than 4-fold higher than any anxiety disorder [1]. In addition to genetic factors [2] and medication adherence [3-5], various clinical and demographic factors are associated with higher risk of relapse and hospitalization, events that are predictive of higher costs [6]. These factors include male gender, lower educational level, unemployment, higher illness chronicity, higher frequency of alcohol consumption, co-occurring alcohol and substance abuse, a history of depression and/or suicide attempts, a history of violence and/or arrests, and recent hospitalization [7-10]. The positive association of these factors with mental health treatment costs suggests that persons who are more vulnerable to crises (i.e., personal life events typically associated with an acute societal intervention) have higher treatment costs than persons who are less vulnerable to these events.

The relationship between crisis events and treatment costs has not been well-studied. Most prior studies of costs are based on administrative data that provide relatively little information about vulnerabilities and recent crises [11]. Information about the relationship of crises to costs is essential for accurate risk adjustment, the process of assigning capitation rates for enrollees of public and private health insurance plans. Capitation rates that are set too low provide plans and HMOs insufficient incentive to treat high-risk, high cost patients [12-14]. Information on the effect of crisis events is particularly valuable at a time when there are concerted efforts to decrease patient hospitalization and manage various types of psychiatric crises in the community. In the United States, for example, the length of hospital stay has gradually declined in the past 10 years [15], attesting to economic and policy-driven pressures to reduce psychiatric hospitalizations. Information about crisis events has also clinical utility in usual care settings, where it may help identify more vulnerable patients with more complex illness trajectories who require specialized interventions and better coordination with other social agencies, including the criminal justice system.

Most prospective longitudinal data do not enable the study of whether patients diagnosed with schizophrenia who have experienced a recent crisis incur higher direct mental health costs compared to patients who have not experienced a crisis. However, the availability of comprehensive clinical, functional and economic data from a large 3-year prospective non-interventional observational study of persons treated for schizophrenia in the United States provided the opportunity to address this topic in some detail. The objective of the current investigation was to assess the relationship between recent crisis events and direct annual mental health costs in patients diagnosed with schizophrenia spectrum disorders in clinical practice settings. The crisis events examined included (1) suicide attempt, (2) psychiatric hospitalization, (3) arrest, (4) violent behavior, and (5) substance use disorder. Five separate propensity score analyses were performed (one for each crisis event) to evaluate the relationship between each crisis event and cost when compared to the group of individuals who did not experience that specific crisis event.

\section{Methods \\ Study design}

Data used in the current analysis are from the U.S. Schizophrenia Care and Assessment Program (US-SCAP), a prospective, non-interventional, non-randomized, 3-year observational study of more than 2300 persons with schizophrenia. The data used in the current analysis consist of the first full year of data available for each patient in the study. The goal of the US-SCAP was to examine the relationship of clinical and treatment variables with outcomes of persons diagnosed with schizophrenia-spectrum disorders who were receiving mental health care in outpatient and inpatient settings at 6 treatment sites. The study, conducted between July 1997 and September 2003, enrolled a total of 2327 patients at 6 health care sites chosen to provide a diverse patient sample in terms of geography, ethnicity, and clinical setting (e.g., university and community mental health centers, Veterans Affairs (VA) hospitals, and community and state hospitals). Sites were only included in the study if they offered open and unrestricted formulary access to all available antipsychotics and were not relying on any algorithms for treatment decision-making. The study protocol was reviewed and approved by the Institutional Review Board (IRB) at each site prior to study initiation, and written informed consent was obtained from all participants.

A detailed description of study design and methods are provided in previous publications [16-18]. Briefly, USSCAP study enrollment was offered to all patients who were 18 years or older who had a DSM-IV diagnosis of schizophrenia, schizoaffective, or schizophreniform disorder. Patients were enrolled regardless of psychiatric or medical comorbidity, use of concomitant medications, or presence of behavioral problems (criminal or otherwise). The goal was to obtain the broadest and most representative sample of schizophrenia-spectrum patients seen in clinical practice settings.

For the purposes of the current cost analysis, a subgroup of US-SCAP enrollees $(n=1557 ; 67 \%)$ was identified who had a full year of information available on mental health resource utilization. If patients had $>1$ year of mental health resource information, the patient's earliest year was used in the current analysis. 
Five crisis subgroups were defined based on the presence of any one of the following events at the start of the 1-year observation period: (1) a suicide attempt in 4 weeks prior to the baseline assessment per patient self report; (2) a psychiatric hospitalization in the 6 months prior to baseline per medical records; (3) an arrest in the 6 months prior to baseline per patient self report; (4) violent behavior in the 4 weeks prior to baseline per patient self report; and (5) a diagnosis of substance use disorder, based on medical record, which occurred at any time during the study period.

\section{Measures}

At study entry, patients completed a semi-structured interview, during which information about psychiatric history and background characteristics was collected. Patients' medical records were systematically abstracted every 6 months by examiners, trained and certified by the contract research organization, using a medical record abstraction form developed for this study that summarized mental health resource utilization during the preceding 6 months. Patients were queried about use of medical and psychiatric services outside of their usual treatment site. Study staff members regularly obtained medical records from treatment sites mentioned by patients. At 6-month intervals, patients also completed the SCAP-Health Questionnaire (SCAP-HQ [19]), a personal interview that includes questions on recent drug and alcohol use (in the past 12 months), suicide attempt (in the past 4 weeks), arrests (in the past 6 months), and violent behavior (in the past 4 weeks). At 1-year intervals, clinical assessments of psychiatric symptoms, medication side-effects, and functioning were completed by trained clinicians.

\section{Assessment of costs}

The total annual direct costs were calculated as the sum of the following component charges: medication costs, including antipsychotics and other psychotropics (the cost of antipsychotics was based on Average Wholesale Price discounted by $15 \%$ for atypical antipsychotics); costs of psychiatric hospitalization (based on the actual charges); and costs of other mental health services (based on Relative Value Units [RVUs; 20,21] developed from management information systems (MIS) data at each site to help address variations across sites in available information about resource types, costs, and durations). The costs of other mental health services included the following cost components: emergency services, day treatment, outpatient medication management by a physician, individual outpatient therapy, outpatient psychosocial group interventions, and case management.

\section{Statistical analyses}

For comparisons of baseline characteristics, t-tests were used for continuous variables and Mantel-Haenszel chi- square tests for categorical variables. In order to correct for potential bias not attributable to membership in a crisis event subgroup, the propensity score method was used to balance the crisis event versus non-crisis event subgroups. The variables selected $a$ priori for calculating the logit score using the propensity method were: age at enrollment, gender, race, illness duration, comorbid affective disorder, comorbid substance use, comorbid personality disorder, diagnosis of mental retardation, insurance status, inpatient status at the beginning of the 1-year observation period, site, and days from July 11997 to the beginning of the study. Substance use was not used in the propensity score model when substance use was being analyzed as the crisis event, and inpatient status was not used in the propensity score model when costs associated with recent psychiatric hospitalizations were estimated.

The propensity score-adjusted bootstrapping method analyzed mean differences of costs between each crisis event and non-crisis event group by first calculating the logit score for each patient based on the above adjustments. Five bins of logit scores were then created for each crisis event group. The bootstrap resampling method was performed by randomly selecting an equal size of sample from each of the 10 bins ( 5 bins for each treatment) into 1 group and calculating the total cost difference between the 2 treatment groups. The above steps were then repeated 1000 times, generating a total of 1000 data points' distribution for testing the null hypothesis using 2-tailed p-values [22]. The propensity score-adjusted bootstrapping method was also used to test the mean differences of costs for the 2 high level crisis event groups: patients with 2 or more crisis-event variables and patients with 3 or more crisis-event variables. This method accommodates the distributional and correlational properties of the data [23]. In addition to mean total cost and cost of psychiatric hospitalization per patient for the index year, we also calculated the mean annual length of psychiatric hospital stay and the mean number of psychiatric hospital admissions per crisis event category. This information aimed at clarifying which type of crisis made a significant and unique contribution to increased costs due to hospitalization, the costliest component in the treatment of schizophrenia. SAS version 8 was used to perform all statistical analyses, with all effects tested at a 2-sided $\alpha$ level of 0.05 [24].

\section{Results}

The total sample used in the cost analysis consisted of the 1557 patients (Table 1) for whom there were at least 1 year of complete medical information during the 3-year study period. For the cost analysis sample, the typical patient was between 30 and 50 years of age, with at least a 10-year history of illness. Almost all (94.9\%) of patients were taking an antipsychotic drug at the time of enroll- 
Table I: Demographic and clinical characteristics of patients at enrollment

\begin{tabular}{|c|c|c|}
\hline \multirow[t]{2}{*}{ Characteristic } & \multicolumn{2}{|c|}{$N=\mid 557$} \\
\hline & $\mathbf{N}$ & $\%$ \\
\hline Male & 948 & 60.9 \\
\hline Single, never married & 938 & 60.5 \\
\hline \multicolumn{3}{|l|}{ Ethnicity } \\
\hline White & 762 & 48.9 \\
\hline Black & 589 & 37.8 \\
\hline Other & 206 & 13.2 \\
\hline \multicolumn{3}{|l|}{ Health insurance } \\
\hline Medicaid/Medicare & 1243 & 81.2 \\
\hline Department of Veteran Affairs & 97 & 6.3 \\
\hline Private insurance & 70 & 4.6 \\
\hline Other coverage & 16 & 1.1 \\
\hline No health insurance & 104 & 6.8 \\
\hline \multirow[t]{2}{*}{ Educational attainment, high school or less } & 1047 & 67.9 \\
\hline & Mean & SD \\
\hline Age, years & 42.4 & 11.1 \\
\hline Age at illness onset, years & 20.7 & 8.9 \\
\hline MADRS total score & 13.6 & 10.2 \\
\hline PANSS total score & 69.1 & 18.4 \\
\hline \multicolumn{3}{|c|}{ Medication days in the 6 months prior to enrollment } \\
\hline Atypical antipsychotic & 96.5 & 87 \\
\hline Typical antipsychotic & 90.1 & 87 \\
\hline Antidepressant & 59.1 & 81.8 \\
\hline Mood stabilizer & 46.7 & 77.3 \\
\hline Other psychotropic & 75.5 & 84.9 \\
\hline
\end{tabular}

PANSS, Positive and Negative Symptoms of Schizophrenia scale MADRS, Montgomery-Åsberg Depression Rating Scale

ment; $38.3 \%$ were also taking an antidepressant, and $31.0 \%$ were also taking a mood stabilizer.

Participants who had incomplete medical information for the purpose of costs calculations $(\mathrm{N}=770)$ were excluded from this study. The excluded patients were similar to the analysis sample $(\mathrm{N}=1557)$ in terms of gender (male: $63 \%$ vs. $60 \% ; \mathrm{p}=.489)$, but were significantly younger $(40.8 \pm$ 11.4 vs. $42.4 \pm 11.1$ years; $\mathrm{p}<.01)$ and were less likely to be African-American ( $32 \%$ vs. $38 \%$ ), but more likely to be Hispanic ( $17 \%$ vs. $13 \%)$ or Caucasian $(51 \%$ or $49 \%$; overall $\mathrm{p}=.013$ ). Compared to the 1557 retained subjects, the excluded group was also more likely to have been hospitalized in the prior 6 months $(15.4 \%$ vs $25.2 \%$, respectively), to be arrested in the prior 6 months $(3.8 \%$ vs $10.1 \%$ ), to manifest violent behaviors in the past 4 weeks $(4.2 \%$ vs $8.4 \%)$ and attempt suicide in the past 4 weeks $(1.2 \%$ vs $3.8 \%)$, but had a similar proportion of persons with substance abuse diagnosis $(36.1 \%$ vs $29.5 \%)$. The excluded group may have experienced a greater interface with the criminal justice system (e.g., jails), thus less likely to have complete mental health information in the present study.
The mean 1-year mental health treatment costs per patient totaled $\$ 16,098$ (Table 2). Te two largest costs were psychotropic medication (30\%) and hospitalization (29\%; Figure 1). The remaining 6 cost component categories comprised $48 \%$ of the total cost, with none contributing more than $10 \%$ (Figure 1). Among the hospitalized participants, the correlation between hospitalization costs and total mental health treatment costs during the index year was high $(\mathrm{r}=.987, \mathrm{p}<.001)$, reflecting the fact that hospitalization is the core driver of total costs.

Sorting patients into crisis event categories yielded 5 overlapping subgroups. The largest subgroups were co-occurring substance use disorder $(\mathrm{n}=413)$ and hospitalized in the past 6 months $(\mathrm{n}=240)$, followed by violent in the past 4 weeks $(n=62)$, arrested in the past 6 months $(n=$ $56)$, and attempted suicide in the past 4 weeks $(n=18)$. Prior to formal matching, each of the crisis event subgroups was not substantially different from each other on most baseline demographic and clinical characteristics (Table 3). The typical patient was most likely to be a male ( $61 \%$ ) between the ages of 30 and 50 years. As expected, the proportion of males was somewhat higher in the subgroup who had been arrested in the past 6 months (80\%) and the subgroup with comorbid substance abuse (74\%). Though the sample size was small $(\mathrm{N}=18)$, the subgroup who had recently attempted suicide was younger (mean age, 34 years), more likely to be female $(61 \%)$, and more likely to have a depressive component, with a mean MADRS score of 31, and a diagnosis of schizoaffective disorder (50\%; Table 3$)$.

The five crisis event categories were not mutually exclusive (Table 4), with highest levels of overlap between substance use disorder, arrest, suicide attempt and violent behavior. A substantial proportion $(46.4 \%)$ of those with arrest, with suicide attempt (44.4\%), and with violent behaviors $(41.9 \%)$ had also a diagnosis of substance abuse. While $21.1 \%$ of those with substance abuse diag-

Table 2: Mean I-year per patient total cost and cost components $(n=1557)$

\begin{tabular}{lc}
\hline Cost component & $\begin{array}{c}\text { Mean Cost }(\$) \\
\text { (standard deviation) }\end{array}$ \\
\hline Total annual cost & $16,098(24,791)$ \\
Medications & $4,817(3,858)$ \\
Antipsychotics & $3,770(3,244)$ \\
Other psychotropics & $1,047(1,313)$ \\
Psychiatric hospitalizations & $4,687(23,536)$ \\
Day Treatment & $1,571(3,734)$ \\
Emergency Services & $84(196)$ \\
Psychosocial group therapy & $1,478(3,126)$ \\
Medication management & $1,187(1,331)$ \\
Individual therapy & $1,267(1,826)$ \\
Case management & $1,006(958)$ \\
\hline
\end{tabular}




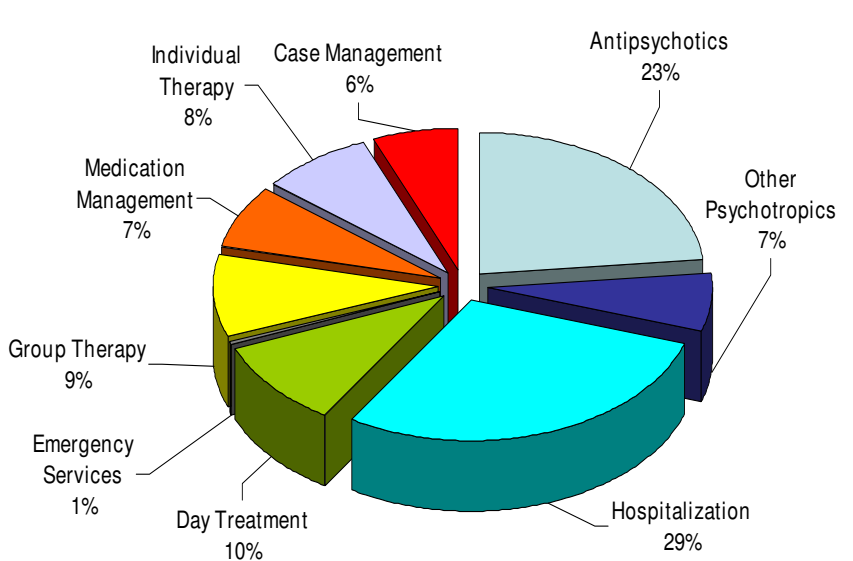

Figure I

Mental health cost components as a proportion of total annual mental health costs. Of the I-year per patient total mental health treatment cost of $\$ 16,098$, the largest single contributor was the cost of hospitalization (29\%), followed by antipsychotic medication (23\%). Each of the remaining 6 cost component categories contributed less than $10 \%$ to the total.

nosis were hospitalized, about a third (36.3\%) of the hospitalized had co-occurring diagnosis of substance abuse. Furthermore, participants with substance use disorders had the lowest mean annual number of hospitalization days (25.5) and a relatively low mean annual number of psychiatric admissions (0.7).

The 1-year hospitalization and total 1-year mental health treatment costs were calculated for each crisis event subgroup, and compared, using a propensity score adjusted bootstrap re-sampling method (repeated 1000 times), to the non-crisis event subgroup. The results of this analysis (summarized in Table 5) found significantly higher mean 1-year hospitalization costs, and total mental health costs, for each crisis event subgroup except comorbid substance abuse. The mean total annual mental health cost for the subgroup who had experienced no crisis event was $\$ 11,739$ per patient. The mean total mental health cost for patients with at least 1 crisis event was $\$ 22,704$ per patient, with the highest cost observed in the subgroup of patients who attempted suicide, followed by patients with a recent psychiatric hospitalization, arrest, violent behavior, and those with comorbid substance use disorder (Table 5). Of the patients $(n=619)$ who qualified for inclusion in at least 1 crisis event subgroup, 30.9\% had experienced only one crisis event, $8.9 \%$ had experienced 2 or more crisis events, and $1.9 \%$ had experienced 3 or more events. The presence of $\geq 2$ and $\geq 3$ crisis events was associated with a significant and step-wise increase in both 1year hospitalization and total 1-year mental health costs compared to the costs in the non-crisis event subgroup, reflecting a high mean number of hospitalization days (72.7 and 101.1 days, respectively) and a high mean number of hospital admissions (1.7 and 2.7, respectively) (Table 6).

\section{Discussion}

Previous research has identified various clinical variables as significant predictors of relapse and hospitalization in patients diagnosed with schizophrenia. The current study extends these findings by providing, for the first time, information on the annual mental health costs associated with experiencing specific crisis events. The use of comprehensive assessments in a prospective naturalistic study with valid and reliable instruments enabled the identification of individuals who had experienced specific crisis events, and the systematic collection of resource utilization data for different types of mental health services. Given the large and diverse sample of schizophrenia patients analyzed and the prospective, naturalistic design, the findings of the study are likely to be applicable to patients with schizophrenia treated in large systems of care across the United States.

Although $60.2 \%$ of the participants did not report experiencing a crisis event, $39.8 \%$ of the patients did, with $30.9 \%$ of all participants meeting only one crisis event criterion, $8.9 \%$ meeting 2 or more criteria, and about $2 \%$ meeting three or more criteria. Thus, the base rate for experiencing a crisis event was not low.

As hypothesized, patients experiencing a crisis event that took place (or at least started) before the 1-year observation period accounted for a preponderance of the total mental health costs during that period. Furthermore, a disproportionate contribution to increased mental health costs was made by the subgroup who reported experiencing 2 or more crisis events. The per patient mean total annual mental health cost for the non-crisis event subgroup was $\$ 11,739$, while patients who reported at least 1 crisis event had a per patient mean of $\$ 22,704$. (Note that the mean total costs shown in Table 5 for each crisis event subgroup are higher, because some of the individuals in each group may have experienced 1 or more additional crisis events.)

The highest annual per patient total mental health cost was in the subgroup of patients who attempted suicide, followed by patients with a recent psychiatric hospitalization. In the current investigation, patients with a concurrent substance use disorder did not appear to have significantly higher total mental health costs compared to those without a substance use disorder. This is an unexpected finding since substance abuse has previously been reported to be a predictor of medication nonadherence $[25,26]$, which, in turn, is often reported to be a highly sig- 
Table 3: Characteristics of patients in each crisis event subgroup prior to propensity score matching

\begin{tabular}{|c|c|c|c|c|c|c|}
\hline \multirow[b]{2}{*}{ Characteristic } & \multicolumn{6}{|c|}{ Crisis events } \\
\hline & $\begin{array}{l}\text { Hospitalized in } \\
\text { past } 6 \text { months }\end{array}$ & $\begin{array}{l}\text { Arrested in past } \\
6 \text { months }\end{array}$ & $\begin{array}{c}\text { Violent in past } 4 \\
\text { weeks }\end{array}$ & $\begin{array}{c}\text { Concurrent } \\
\text { substance abuse }\end{array}$ & $\begin{array}{c}\text { Attempted } \\
\text { suicide in past } 4 \\
\text { weeks }\end{array}$ & $\begin{array}{c}\text { Non-crisis event } \\
\text { subgroup }\end{array}$ \\
\hline \multicolumn{7}{|l|}{ Sample sizes } \\
\hline Yes & 240 & 56 & 62 & 413 & 18 & 938 \\
\hline No & 1317 & 1469 & 1463 & 1144 & 1507 & 619 \\
\hline \multicolumn{7}{|l|}{ Age, years } \\
\hline Yes & $39(10.3)$ & $38.9(9.7)$ & $40.7(10.0)$ & $39.9(9.8)$ & $33.8(11.0)$ & 43.9 (II.4) \\
\hline No & 43 (1I.2) & 42.6 (II.I) & $42.5(11.1)$ & 43.2 (II.4) & 42.6 (11.0) & $40(10.2)$ \\
\hline \multicolumn{7}{|l|}{$\begin{array}{l}\text { Age of Illness } \\
\text { onset, yrs }\end{array}$} \\
\hline Yes & $19.8(8.6)$ & $19.4(6.3)$ & $18.9(7.8)$ & $19.4(8.3)$ & $16.4(5.8)$ & $21.4(9.1)$ \\
\hline No & $20.8(8.9)$ & $20.8(9.0)$ & $20.8(9.0)$ & $21.1(9.0)$ & $20.8(9.0)$ & $19.6(8.5)$ \\
\hline \multicolumn{7}{|l|}{$\begin{array}{l}\text { MADRS total } \\
\text { score }\end{array}$} \\
\hline Yes & $15.6(11.0)$ & $14.0(10.5)$ & $19.9(12.0)$ & $13.5(10.8)$ & $30.9(12.5)$ & I3.I (9.8) \\
\hline No & $13.2(10.0)$ & $13.5(10.1)$ & $13.3(10.0)$ & $13.6(10.0)$ & $13.4(10.0)$ & $14.3(10.8)$ \\
\hline \multicolumn{7}{|l|}{ PANSS total score } \\
\hline Yes & $73.9(18.4)$ & 7I.I (15.7) & $72.0(18.8)$ & $69.6(19.1)$ & $86.7(16.9)$ & $68.0(17.8)$ \\
\hline No & $68.2(18.2)$ & $69.1(18.5)$ & $69.0(18.4)$ & $68.9(18.0)$ & $69.0(18.3)$ & $70.8(19.0)$ \\
\hline \multicolumn{7}{|l|}{$\begin{array}{l}\text { Medication days in } \\
6 \text { mos. prior to } \\
\text { enrollment }\end{array}$} \\
\hline \multicolumn{7}{|l|}{ Atypicals } \\
\hline Yes & $96.2(82.9)$ & $61.7(81.1)$ & $71.2(84.4)$ & $91.0(87.0)$ & $89.3(82.2)$ & $98.6(87.5)$ \\
\hline No & $96.6(87.7)$ & 97.7 (86.9) & $97.4(86.9)$ & $98.5(86.9)$ & $96.5(87.0)$ & $93.4(86.2)$ \\
\hline \multicolumn{7}{|l|}{ Typicals } \\
\hline Yes & $72.2(82.0)$ & $95.9(82.9)$ & $98.4(88.8)$ & $98.1(86.5)$ & $60.9(80.8)$ & $90.3(87.6)$ \\
\hline No & 93.4 (87.4) & $89.8(87.1)$ & 89.7 (86.9) & $87.2(86.9)$ & $90.4(87.0)$ & $89.7(85.8)$ \\
\hline \multicolumn{7}{|l|}{ Antidepressant } \\
\hline Yes & $54.2(78.9)$ & $55.1(81.0)$ & $71.2(84.4)$ & $53.1(80.0)$ & $74.7(86.6)$ & $61.3(82.6)$ \\
\hline No & $60(82.3)$ & $59.6(82.0)$ & $58.9(81.8)$ & $61.3(82.4)$ & $59.2(81.9)$ & $55.9(80.6)$ \\
\hline \multicolumn{7}{|l|}{ Mood stabilizer } \\
\hline Yes & $64.1(82.0)$ & $41.3(74.3)$ & $46.4(77.1)$ & 38.7 (7I.7) & $61.0(84.1)$ & $45.5(77.3)$ \\
\hline No & $43.5(76.0)$ & 47.0 (77.5) & $46.8(77.4)$ & $49.6(79.1)$ & $46.6(77.3)$ & $48.6(77.4)$ \\
\hline \multicolumn{7}{|l|}{$\begin{array}{l}\text { Other } \\
\text { psychotropic }\end{array}$} \\
\hline Yes & $71.0(80.5)$ & $63.8(79.9)$ & 99.1 (82.5) & $79.3(85.4)$ & 36.1 (63.3) & 74.1 (85.5) \\
\hline No & 76.4 (85.7) & $75.7(85.0)$ & $74.3(84.8)$ & $74.2(84.8)$ & $75.7(85.0)$ & 77.7 (84.2) \\
\hline \multicolumn{7}{|l|}{ Male, N (\%) } \\
\hline Yes & 142 (59.2) & $45(80.4)$ & $38(6 \mid .3)$ & $304(73.6)$ & 7 (38.9) & $527(56.2)$ \\
\hline No & $806(6 \mid .2)$ & $882(60.0)$ & $889(60.8)$ & $644(56.3)$ & $920(61.0)$ & 421 (68.0) \\
\hline \multicolumn{7}{|l|}{ Single, N (\%) } \\
\hline Yes & 149 (62.3) & $46(82.0)$ & $26(4 \mid .9)$ & $262(63.8)$ & II (6I.I) & $549(58.8)$ \\
\hline No & 789 (60.2) & $871(59.6)$ & $891(61.2)$ & $676(59.4)$ & $906(60.4)$ & $389(63.2)$ \\
\hline \multicolumn{7}{|l|}{ Diagnosis, N (\%) } \\
\hline \multicolumn{7}{|l|}{ Schizophrenia } \\
\hline Yes & $119(49.6)$ & $33(58.9)$ & $32(51.6)$ & $257(62.2)$ & $9(50.0)$ & $620(66.1)$ \\
\hline No & $861(65.4)$ & $926(63.0)$ & $927(63.4)$ & $723(63.2)$ & $950(63.0)$ & $360(58.2)$ \\
\hline \multicolumn{7}{|l|}{ Schizoaffective } \\
\hline Yes & 103 (42.9) & $17(30.4)$ & $28(45.2)$ & $125(30.3)$ & $9(50.0)$ & $282(30.1)$ \\
\hline No & $393(29.8)$ & $469(31.9)$ & $458(31.3)$ & $371(32.4)$ & $477(31.7)$ & $214(34.6)$ \\
\hline \multicolumn{7}{|l|}{$\begin{array}{l}\text { Other } \\
\text { psychotic }\end{array}$} \\
\hline Yes & $19(7.9)$ & $6(10.7)$ & $2(3.2)$ & $31(7.5)$ & 0 & $38(4.1)$ \\
\hline No & 65 (4.9) & $77(5.2)$ & $81(5.5)$ & $53(4.6)$ & $83(5.5)$ & $46(7.4)$ \\
\hline
\end{tabular}

Means (standard deviations) unless otherwise specified. Patients may belong to more than one subgroup. Yes $=$ with event; No $=$ without event. PANSS, Positive and Negative Symptoms of Schizophrenia scale

MADRS, Montgomery-Åsberg Depression Rating Scale

Atypicals $=$ atypical antipsychotics

Typicals = typical antipsychotics 
nificant predictor of future relapse and hospitalization [27-29]. One possible explanation is suggested by recent data from the Clinical Antipsychotic Trials in Intervention Effectiveness (CATIE) study which found that substance abuse was a marker for higher psychosocial functioning in schizophrenia [30]. Another possibility is that some of the substance abusing participants - especially those with prior arrests and violent behaviors- had more extensive interface with the criminal justice system (e.g., jails), thus some of their costs may have shifted from the mental health to the criminal justice system. In addition, nonadherence with medication may also underlie the higher costs incurred by patients in the other crisis event categories, since nonadherence with antipsychotic medication was previously found to be associated not only with psychiatric hospitalizations but also with a higher risk of violent behaviors, arrests and suicide attempts [29]. While detecting ongoing medication nonadherence may be difficult and challenging in usual care settings, the occurrence of a crisis event is apt to be more readily identifiable, thus serve as a clinical marker of patients' greater vulnerability from a clinical and functional perspective. This may turn out to be a convenient way of targeting subsets of patients with different illness profiles (e.g., with different diagnostic characteristics, illness trajectories, or vulnerability factors) and effectively treating individuals who experience crisis events.

Cost differences among patients who experience a crisis event appeared to be primarily driven by the cost of psychiatric hospitalization, with a strong and significant correlation $(r=.99)$ between hospitalization cost and total annual mental health costs. In the current analysis, hospitalization comprised, however, only $29 \%$ of the total annual mental health costs, while antipsychotic medica- tion comprised $23 \%$. This finding is inconsistent with prior research in which the cost attributed to hospitalization was of larger proportion- about $50 \%-80 \%$ - of the total cost $[31,32]$. The reason for the inconsistency is unclear. The relatively low percentage attributed to hospitalization may reflect the way that costs were calculated in the present study. Specifically, the cost of psychiatric hospitalization was based on actual charges while the cost of antipsychotics was based on Average Wholesale Price discounted by $15 \%$ and the cost of other non-hospitalization mental health services was based on Relative Value Units. It is possible, therefore, that the methods of estimating non-hospitalization costs led to their overestimation relative to hospitalization cost. Furthermore, the relative cost contribution of hospitalization and antipsychotic medication to overall total direct costs would be substantially lower in the current study if non-psychiatric medical costs and direct non-health care costs had been available for analysis.

\section{Study limitations}

The study has important limitations which deserve to be highlighted. First, the criteria for several of the crisis event subgroups (attempted suicide, arrested, violent) were based on a patient-reported measure, not on objective data. It should also be noted that substance abuse is not, strictly speaking, a discrete event, but an ongoing condition. Second, the sample sizes for several of the crisis event subgroups were small, most notably for the "attempted suicide" group. The appropriateness of the propensity score adjusted bootstrap re-sampling method with such small sample sizes may be questionable. Third, some hospitalizations may have been underreported since stays in state psychiatric hospitals may not have been reported by all patients, and such hospitalizations would have been

Table 4: Proportion of participants in each crisis event category and degree of overlap between categories

\begin{tabular}{|c|c|c|c|c|c|}
\hline & $\begin{array}{l}\text { Hospitalized in } \\
\text { prior } 6 \text { months }\end{array}$ & $\begin{array}{l}\text { Arrested in } \\
\text { previous } 6 \text { months }\end{array}$ & $\begin{array}{l}\text { Violent behavior in } \\
\text { previous } 4 \text { weeks }\end{array}$ & $\begin{array}{c}\text { Concurrent } \\
\text { substance abuse } \\
\text { diagnosis }\end{array}$ & $\begin{array}{l}\text { Attempted suicide } \\
\text { in past } 4 \text { weeks }\end{array}$ \\
\hline $\begin{array}{l}\text { Hospitalized in } \\
\text { prior } 6 \text { months } \\
(\mathrm{N}=240)\end{array}$ & - & 22 (9.2\%) & 17 (7.1\%) & 87 (36.3\%) & II (4.6\%) \\
\hline $\begin{array}{l}\text { Arrested in } \\
\text { previous } 6 \text { months } \\
(\mathrm{N}=56)\end{array}$ & $22(39.3 \%)$ & - & 5 (8.9\%) & $26(46.4 \%)$ & I (I.8\%) \\
\hline $\begin{array}{l}\text { Violent behavior in } \\
\text { previous } 4 \text { weeks } \\
(\mathrm{N}=62)\end{array}$ & I7 (27.4\%) & 5 (8.1\%) & - & 26 (4I.9\%) & 2 (3.2\%) \\
\hline $\begin{array}{l}\text { Concurrent } \\
\text { substance abuse } \\
\text { diagnosis } \\
(\mathbf{N}=4 \mid 3)\end{array}$ & 87 (21.1\%) & $26(6.6 \%)$ & 26 (6.6\%) & - & $8(2.0 \%)$ \\
\hline $\begin{array}{l}\text { Attempted suicide } \\
\text { in past } 4 \text { weeks } \\
(N=18)\end{array}$ & II (6I.I\%) & I (5.6\%) & 2 (II.I\%) & 8 (44.4\%) & - \\
\hline
\end{tabular}


Table 5: Mean I-year total costs, hospitalization costs and hospitalization parameters for patients with and without specific crisis event categories

\begin{tabular}{|c|c|c|c|c|c|c|}
\hline & \multicolumn{2}{|c|}{ Patients with event } & \multirow{2}{*}{$\begin{array}{l}\text { Mean I-year total } \\
\text { mental health cost } \\
\text { per patient }\end{array}$} & \multirow{2}{*}{$\begin{array}{c}\text { Mean I-year cost of } \\
\text { psych hospitalization } \\
\text { per patient }\end{array}$} & \multirow{2}{*}{$\begin{array}{l}\text { Mean number of } \\
\text { days hospitalized }\end{array}$} & \multirow{2}{*}{$\begin{array}{c}\text { Mean number of } \\
\text { hospital } \\
\text { admissions }\end{array}$} \\
\hline & $\mathbf{N}$ & $\%$ & & & & \\
\hline \multicolumn{7}{|c|}{$\begin{array}{l}\text { Hospitalization in } \\
\text { previous } 6 \text { months }\end{array}$} \\
\hline Yes & 240 & 15.4 & $\$ 37,329$ ** & $\$ 23,962 * *$ & 73.3 & 1.9 \\
\hline No & 1317 & 84.6 & $\$ 12,229$ & $\$ 1,175$ & 4.8 & 0.3 \\
\hline \multicolumn{7}{|c|}{$\begin{array}{l}\text { Arrested in } \\
\text { previous } 6 \text { months }\end{array}$} \\
\hline Yes & 56 & 3.7 & $\$ 31,081 *$ & $\$ 20,334 *$ & 55.8 & 1.1 \\
\hline No & 1469 & 96.3 & $\$ 15,654$ & $\$ 4,180$ & 14.1 & 0.5 \\
\hline \multicolumn{7}{|c|}{$\begin{array}{l}\text { Violent behavior in } \\
\text { previous } 4 \text { weeks }\end{array}$} \\
\hline Yes & 62 & 4.1 & $\$ 18,778$ ** & $\$ 7,416 * *$ & 29.6 & 1.3 \\
\hline No & 1463 & 95.9 & $\$ 16,113$ & $\$ 4,661$ & 15.1 & 0.5 \\
\hline \multicolumn{7}{|c|}{$\begin{array}{l}\text { Concurrent } \\
\text { substance abuse } \\
\text { disorder }\end{array}$} \\
\hline Yes & 413 & 26.5 & $\$ 19,034$ & $\$ 7,455$ & 25.5 & 0.7 \\
\hline No & 1144 & 73.5 & $\$ 15,038$ & $\$ 3,688$ & 11.7 & 0.5 \\
\hline \multicolumn{7}{|c|}{$\begin{array}{l}\text { Attempted suicide } \\
\text { in past } 4 \text { weeks }\end{array}$} \\
\hline Yes & 18 & 1.2 & $\$ 46,024 * *$ & $\$ 30,080 * *$ & 61.8 & 1.3 \\
\hline No & 1507 & 98.8 & $\$ 15,865$ & $\$ 4,47 \mid$ & 15.1 & 0.5 \\
\hline
\end{tabular}

$* \mathrm{P}<.05 ;$ ** $\mathrm{P}<.01$; $\mathrm{P}$ values compare non-crisis event group cost ("no") vs. crisis event group cost ("yes") for each event.

missed by most of the MIS systems. Fourth, emergency department visits may have also be significantly underreported, since they would not have been captured by MIS or by medical record in most cases. This might help to explain why the estimate of emergency department costs was negligible in the current study. Fifth, an estimation bias may have occurred in the calculation of medication costs using average wholesale price (AWP; discounted by $15 \%$ for atypical antipsychotics). The AWP may not reflect variations in medication costs and greater discount rates across different health care systems. A final limitation is that the estimates reported in this paper are for mental health costs only and do not include non-psychiatric medical costs or direct non-health care costs (e.g., patient involvement in the criminal justice system, use of homeless shelters) - the latter alone have been estimated at $\$ 9.3$ billion per year [2]. The omission of these cost categories has likely resulted, in the current analysis, in an overestimate of the relative contribution of some cost categories. Future cost studies should include data on direct nonhealth care costs, especially since the mental health cost burden is being increasingly shifted to the criminal justice system.

\section{Conclusion}

Mental health costs of treating patients diagnosed with schizophrenia and related disorders are highly heterogeneous. Patients who experience crisis events, particularly

Table 6: Mean I-year costs for patients with and without specific number of crisis event categories

\begin{tabular}{|c|c|c|c|c|}
\hline & \multicolumn{4}{|c|}{ Number of types of crisis events } \\
\hline & None & One only & Two or more & Three or more \\
\hline Patients with event, $\mathrm{N}(\%)$ & $938(60.2 \%)$ & $48 \mathrm{I}(30.9 \%)$ & 138 (8.9\%) & $29(1.9 \%)$ \\
\hline Mean I-year cost of hospitalization per patient & $\$ 830$ & $\$ 6,912 *$ & $\$ 23,149 *$ & $\$ 33,199 *$ \\
\hline Mean I-year total mental health cost per patient & $\$ 11,739$ & $\$ 19,066 *$ & $\$ 35,385 *$ & $\$ 44,599 *$ \\
\hline Mean number of days hospitalized & 3.7 & 21.8 & 72.7 & 101.1 \\
\hline Mean number of hospital admissions & 0.2 & 0.8 & 1.7 & 2.7 \\
\hline
\end{tabular}

$* \mathrm{P}<.0 \mathrm{I} ; \mathrm{P}$ values based on non-crisis event group vs. each category: patients with only one type of crisis event, two or more types of events, and three of more types of crisis events. 
those with a recent suicide attempt or psychiatric hospitalization, tend to incur the highest annual mental health costs, driven primarily by the cost of psychiatric hospitalization. Patients involved in the criminal justice system (with prior arrest) also accrue relatively high costs within the mental health delivery system. More prospective research, in usual care settings, is needed to identify high risk patients and to determine which interventions are the most cost effective.

\section{Abbreviations}

AWP: average wholesale price; CATIE: Clinical Antipsychotic Trials in Intervention Effectiveness; MADRS: Montgomery-Åsburg Depression Rating Scale; MIS: management information system; PANSS: Positive and Negative Syndrome Scale; RVUs: Relative Value Units; SCAP-HQ: SCAP-Health Questionnaire; TD: tardive dyskinesia; US-SCAP: U.S. Schizophrenia Care and Assessment Program; VA: Veterans Affairs.

\section{Competing interests}

Baojin Zhu, Haya Ascher-Svanum, Douglas Faries and Xiaomei Peng are full-time employees and minor stockholders of Eli Lilly and Company, the sponsor of the study.

David Salkever and Eric P. Slade have no competing financial or non-financial interests.

\section{Authors' contributions}

$\mathrm{BZ}$ performed the statistical analyses, participated in the design of the study, the analytical plan, the interpretation of the results, and assisted in drafting the manuscript. HA-S conceived of the study, participated in its design, the analytical plan, the interpretation of the results, and helped draft the manuscript. DEF participated in the design of the study, the analytical plan, the interpretation of the results, and assisted in drafting the manuscript. XP performed additional statistical analyses. DS and EPS participated in the design of the study, the analytical plan, the interpretation of the results, and assisted in drafting the manuscript. DS and EPS were also involved in preparing the resource utilization costing data of US-SCAP.

\section{Acknowledgements}

Financial support for this research was provided by a grant from Eli Lilly and company. The authors also wish to thank the US-SCAP site investigators and others who collaborated in the research. By site, they include Maryland: A. F. Lehman, M.D., M.S.P.H., University of Maryland School of Medicine, and G. Gallucci, M.D., M.H.S., Johns Hopkins Bayview Medical Center (previously); Colorado: C. Harding, Ph.D., University of Colorado (previously); Florida: D. Shern, Ph.D., Florida Mental Health Institute, University of South Florida (previously), and T. Saunders, M.S., Florida Mental Health Institute (previously); North Carolina: J. Swanson, Ph.D., L. A. Dunn, M.D., and M. Swartz, M.D., Duke University Medical School; California: R. L. Hough, Ph.D., and C. Barrio, Ph.D., Child and Adolescent Services Research Center and San Diego State University; Connecticut: R. A. Rosenheck, M.D., and R.
Desai, Ph.D., VA Connecticut Health Care System; Medstat Group: P. Russo, Ph.D., M.S.W., R.N., (previously), L. Palmer, Ph.D., L. Torres, M.B.A., and B. Cuffel, Ph.D. (previously); Eli Lilly and Co.: D. Buesching, Ph.D., Bryan M. Johnstone, Ph.D., and T. Croghan, M.D. (previously); Consultants: D. Salkever, Ph.D., Johns Hopkins University (previously), E. Slade, Ph.D., Johns Hopkins University (previously), and W. Hargreaves, Ph.D., and M. Shumway, Ph.D., University of California, San Francisco. The authors wish to thank Paul Crits-Christoph, PhD, who was compensated by Eli Lilly and Company, for his valuable assistance with the preparation of the manuscript.

\section{References}

I. Andlin-Sobocki P, Jönsson B, Wittchen HU, Olesen J: Cost of disorders of the brain in Europe. Eur J Neurol 2005, I 2(SuppI I): I-27.

2. Fanous AH, Oord EJ van den, Riley BP, Aggen SH, Neale MC, O'Neill FA, Walsh D, Kendler KS: Relationship between a high-risk haplotype in the DTNBP I (dysbindin) gene and clinical features of schizophrenia. Am J Psychiatry 2005, 162: |824-|832.

3. Weiden PJ, Olfson M: Cost of relapse in schizophrenia. Schizophr Bull 1995, 21:419-429.

4. Gilmer TP, Dolder CR, Lacro JP, Folsom DP, Lindamer L, Garcia P, Jeste DV: Adherence to treatment with antipsychotic medication and health care costs among Medicaid beneficiaries with schizophrenia. Am J Psychiatry 2004, 16 I:692-699.

5. Knapp M, King D, Pugner K, Lapuerta P: Non-adherence to antipsychotic medication regimens: associations with resource use and costs. BrJ Psychiatry 2004, I 84:509-5I6.

6. Gibson PJ, Damler R, Jackson EA, Wilder T, Ramsey JL: The impact of olanzapine, risperidone, or haloperidol on the cost of schizophrenia care in a medicaid population. Value Health 2004, 7:22-35.

7. Carr VJ, Lewin TJ, Neil AL, Halpin SA, Holmes S: Premorbid, psychosocial and clinical predictors of the costs of schizophrenia and other psychoses. Br J Psychiatry 2004, 184:517-525.

8. Almond S, Knapp M, Francois C, Toumi M, Brugha T: Relapse in schizophrenia: costs, clinical outcomes and quality of life. $\mathrm{Br}$ J Psychiatry 2004, I84:346-35I.

9. Haro JM, Novick D, Suarez D, Alonso J, Lépine JP, Ratcliffe M, SOHO Study Group: Remission and relapse in the outpatient care of schizophrenia: three-year results from the Schizophrenia Outpatient Health Outcomes study. J Clin Psychopharmacol 2006, 26:57I-578.

10. Moeller KE, Shireman TI, Liskow BI: Relapse rates in patients with schizophrenia receiving aripiprazole in comparison with other atypical antipsychotics. J Clin Psychiatry 2006, 67:1942-1947.

II. Sernyak MJ, Rosenheck R: Risk adjustment in studies using administrative data. Schizophr Bull 2003, 29:267-27I.

12. Ettner SL, Frank RG, McGuire TG, Hermann RC: Risk adjustment alternatives in paying for behavioral health care under Medicaid. Health Serv Res 200I, 36:793-8II.

13. Frank RG, McGuire TG, Bae JP, Rupp A: Solutions for adverse selection in behavioral health care. Health Care Financ Rev 1997, 18:109-122.

14. Dickey B, Azeni H: Persons with dual diagnoses of substance abuse and major mental illness: their excess costs of psychiatric care. Am J Public Health 1996, 86:973-977.

15. Mojtabai R, Herman D, Susser ES, Sohler N, Craig TJ, Lavelle J, Bromet EJ: Service use and outcomes of first-admission patients with psychotic disorders in the Suffolk County Mental Health Project. Am J Psychiatry 2005, 162:129I-I298.

16. Ascher-Svanum H, Zhu B, Faries D, Ernst FR: A comparison of olanzapine and risperidone on the risk of psychiatric hospitalization in the naturalistic treatment of patients with schizophrenia. Ann Gen Hosp Psychiatry 2004, 3:II.

17. Salkever DS, Slade EP: Employment retention by persons with schizophrenia employed in non-assisted jobs. Journal of Rehabilitation 2003, 69: 18-25.

18. Salkever DS, Slade EP, Karakus M, Palmer L, Russo P: Estimation of antipsychotic effects on hospitalization risk in a naturalistic study with selection on unobservables. J Nerv Ment Dis 2004, 192: II9-128.

19. Lehman AF, Fischer EP, Postrado L, Delahanty J, Johnstone BM, Russo PA, Crown WH: The Schizophrenia Care and Assessment 
Program Health Questionnaire (SCAP-HQ): an instrument to assess outcomes of schizophrenia care. 2003, 29:247-256.

20. Vaul JH: DRG benchmarking study establishes national coding norms. Healthc Financ Manage 1998, 52(5):52-54.

21. Hsiao WC, Braun P, Dunn D, Becker ER: Resource-based relative values. An overview. JAMA 1988, 260:2347-2353.

22. Good P: Permutation tests: a practical guide to resampling methods of testing hypotheses New York (NY): Spring-Verlag; 2000.

23. Altman D: Practical statistics for medical research New York: Chapman \& Hall/CRC; 1999:126-I30.

24. SAS Institute Inc: SAS/STAT user's guide, version 8 Volume I. Cary, NC: SAS Institute, Inc; 1999.

25. Lacro JP, Dunn LB, Dolder CR, Leckband SG, Jeste DV: Prevalence of and risk factors for medication nonadherence in patients with schizophrenia: a comprehensive review of recent literature. J Clin Psychiatry 2002, 63:892-909.

26. Ascher-Svanum H, Zhu B, Faries D, Lacro JP, Dolder CR: A prospective study of risk factors for nonadherence with antipsychotic medication in the treatment of schizophrenia. J Clin Psychiatry 2006, 67: III4-II 23.

27. Svarstad BL, Shireman TI, Sweeney JK: Using drug claims data to assess the relationship of medication adherence with hospitalization and costs. Psychiatr Serv 200I, 52:805-8I I.

28. Valenstein M, Copeland LA, Blow FC, McCarthy JF, Zeber JE, Gillon $L$, Bingham CR, Stavenger T: Pharmacy data identify poorly adherent patients with schizophrenia at increased risk for admission. Med Care 2002, 40:630-639.

29. Ascher-Svanum H, Faries DE, Zhu B, Ernst FR, Swartz MS, Swanson JW: Medication adherence and long-term functional outcomes in the treatment of schizophrenia in usual care. J Clin Psychiatry 2006, 67:453-460.

30. Swartz MS, Wagner HR, Swanson JW, Stroup TS, McEvoy JP, McGee M, Miller del D, Reimherr F, Khan A, Cañive JM, Lieberman JA: Substance use and psychosocial functioning in schizophrenia among new enrollees in the NIMH CATIE study. Psychiatr Serv 2006, 57: $1110-1116$.

31. Fitzgerald PB, Montgomery W, de Castella AR, Filia KM, Filia SL, Christova L, Jackson D, Kulkarni J: Australian Schizophrenia Care and Assessment Programme: real-world schizophrenia: economics. Aust N Z J Psychiatry 2007, 41:819-829.

32. Kashner TM, Rush AJ, Crismon ML, Toprac M, Carmody TJ, Miller AL, Trivedi MH, Wicker A, Suppes T: An empirical analysis of cost outcomes of the Texas Medication Algorithm Project. Psychiatr Serv 2006, 57:648-59.

\section{Pre-publication history}

The pre-publication history for this paper can be accessed here:

http://www.biomedcentral.com/1471-244X/8/72/pre

pub

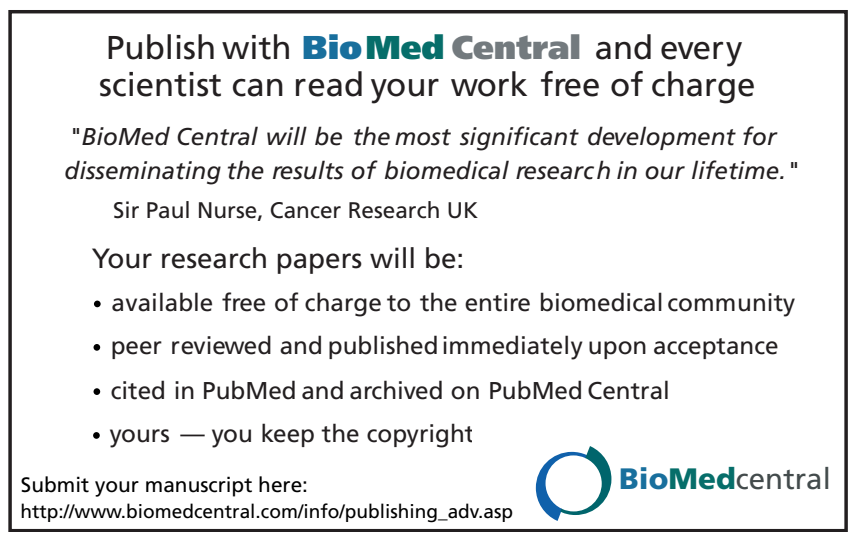

